\title{
CARTA AL DIRECTOR
}

\section{Cribado nasal del Staphylococcus aureus en una unidad de hemodialisis}

\author{
Olga García Ruiz \\ Rosana Yuste Codes \\ Beatriz Mirabet Sáez \\ Noelia Abad Lluch \\ Ana Cristina Moral Aguilar \\ Belén Villa Juliá
}

Centro de Hemodiálisis Cediat-Aldaia.

Alcer Turia. Valencia

\section{Sra. Directora:}

Una de las principales causas de morbilidad en los pacientes en hemodiálisis (HD) sigue siendo la infección del acceso. Diversos estudios cifran de manera global el riesgo en 4.6 infecciones/1000 sesiones $\mathrm{HD}$, con una variabilidad que oscila entre las 2.5 infecciones/1000 sesiones HD para FAV nativas y prótesis o las 18.4 infecciones/1000 sesiones HD si hablamos de catéteres no tunelizados.

El germen más frecuentemente implicado es el Staphylococcus aureus y su aparición está relacionada con la interrupción frecuente de barreras naturales como son la cutánea y mucosa, donde anida una flora común formada por estafilococos y estreptococos, así como otros organismos aerobios e incluso anaerobios.

Algunos trabajos al analizar las características microbiológicas de estos estafilococos han lanzado la hipótesis de un frecuente origen endógeno, de modo que el estudio de los reservorios naturales, como la nariz, tiene una importancia fundamental. De hecho, la prevalencia de portadores nasales de Staphylococcus aureus en pacientes en HD está alrededor de un $50 \%$.

En Enero de 2004 nos planteamos hacer un cribado de todos los pacientes que seguían el tratamiento de $\mathrm{HD}$ en nuestro centro, así como de todo el personal de Enfermería y auxilia-

$$
\begin{gathered}
\text { Correspondencia: } \\
\text { Olga García Ruiz } \\
\text { Cediat-Aldaia (Alcer Turia) } \\
\text { C/ Joaquín Blume, no } 12 . \\
46960 \text { Aldaia (Valencia) } \\
\text { e-mail: cediat.aldaia@alcerturia.org }
\end{gathered}
$$

res que de manera habitual manipularan los accesos vasculares, bien porque los pinchaban y/o conectaban, o porque tras la desconexión, ayudaban a su hemostasia.

\section{OBJETIVOS}

- Conocer la prevalencia de portador nasal de Staphylococcus aureus en nuestra unidad.

- Analizar retrospectivamente las infecciones de los accesos vasculares en los últimos 32 meses y su relación con el estado de portador.

- Establecer un protocolo de profilaxis de infecciones en los sujetos portadores nasales de Staphylococcus aureus

\section{MATERIAL Y MÉTODOS}

Atendiendo a las recomendaciones de las Guías Europeas basadas principalmente en medidas preventivas, actuamos según unos protocolos de asepsia estricta, tanto en la manipulación de catéteres como en la punción de los accesos vasculares (fístulas e injertos arterio-venosos).

Además, se estableció un protocolo de profilaxis determinando la presencia del Staphylococcus aureus en el exudado nasal a todos los pacientes y personal de Enfermería y auxiliares a su entrada en el centro. El procedimiento consiste:

- Obtención de muestra de ambas fosas nasales mediante una torunda y su posterior cultivo.

- Los casos positivos son tratados con mupirocina en pomada, aplicándola en ambas fosas nasales cada 12 horas y durante los primeros cinco días de cada mes.

- La duración del tratamiento es ilimitada

- Control anual de seguimiento. 
Cada una de las enfermeras tenemos asignado un número determinado de pacientes, con el fin de individualizar su seguimiento y servirles de apoyo ante las necesidades y/o dudas que se les puedan presentar. El control lo realizamos a través del programa informático NEFROSOFT ${ }^{\circledR}$ que nos permite llevar a cabo un Proceso de Atención de Enfermería (PAE) en todas sus etapas.

De esta manera, Enfermería podemos actuar planificando los cuidados y tareas en función de las incidencias que puedan surgir, conociendo además el estado evolutivo de cada uno de los pacientes. En el caso concreto de las infecciones por Staphylococcus aureus, podemos mantener una estrecha vigilancia de los portadores nasales y seguir la evolución de su tratamiento, así como la prevención de posibles infecciones de los accesos.

\section{RESULTADOS}

El estudio lo realizamos sobre un total de 52 pacientes que reciben tratamiento de $\mathrm{HD}$ en nuestro centro y 9 enfermeras/auxiliares que están en contacto con ellos.

Los resultados (figura 1) que obtuvimos de la analítica fueron los siguientes:

- 13 pacientes resultaron ser portadores nasales de Staphylococcus aureus, lo que supone una prevalencia del 25\%.

- 1 enfermera de todo el personal, es decir, 11.1\% de prevalencia.

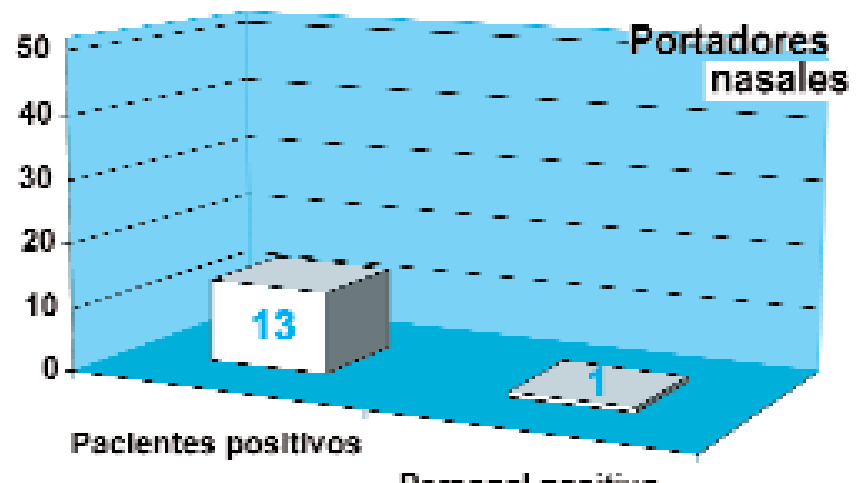

Personal positivo

Figura 1. Resultados del primer cribado nasal.

Haciendo un análisis retrospectivo de los casos de infección de los accesos vasculares durante el periodo de tiempo comprendido entre Junio de 2001 y Enero de 2004, 32 meses, observamos que se habían producido 16 episodios infecciosos en
14 pacientes, de los cuales 6 habían sido infecciones en catéteres, 3 en prótesis y 7 en FAV antólogas (figura 2).

घatćteres | prótesis $\quad$ F $\Lambda \mathrm{V}$ autólogas

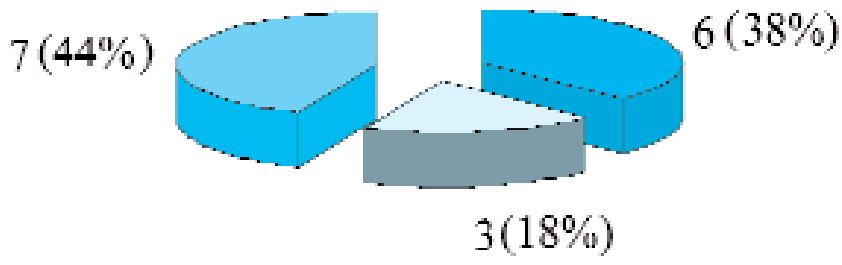

Figura 2. Infecciones de los accesos.

De los 14 pacientes que habían padecido algún proceso infeccioso, 10 pasaron por el cribado de S. aureus y los 4 restantes ya no se encontraban en el centro por causas diversas, bien porque habían sido trasplantados, trasladados o por defunción. De los 10 pacientes estudiados, 5 resultaron ser portadores del S. aureus (36\% del total) y los otros 5 fueron negativos.

Del análisis retrospectivo de los 16 infecciones documentadas en nuestra unidad en el periodo del estudio, 7 (44\%) tuvieron lugar en los pacientes portadores de S. aureus nasal y 5 en pacientes no portadores nasales, aunque en 2 de los episodios pudimos comprobar que la enfermera que había manipulado su acceso (punción, conexión y/o desconexión) el día anterior a la aparición de la infección, también era positiva (figura 3).

El tratamiento de las infecciones fue con vancomicina i.v., según protocolo establecido en nuestro centro, obteniendo una buena respuesta a la antibioterapia.

\section{CONCLUSIONES}

- Aunque la prevalencia de los portadores nasales en nuestro centro es de un 25\%, menor de lo que la literatura señala en líneas generales, sigue suponiendo un alto riesgo de infecciones de los accesos sobre el que podemos actuar, previniendo además otros problemas mayores que pueden ir asociados a la posibilidad de aparición de una bacteriemia.

- Es importante incidir en las medidas de asepsia del personal que mantenga contacto directo con los accesos vasculares de los pacientes, así como hacer hincapié en que adquieran unos buenos hábitos higiénicos y autocuidados de sus accesos. 


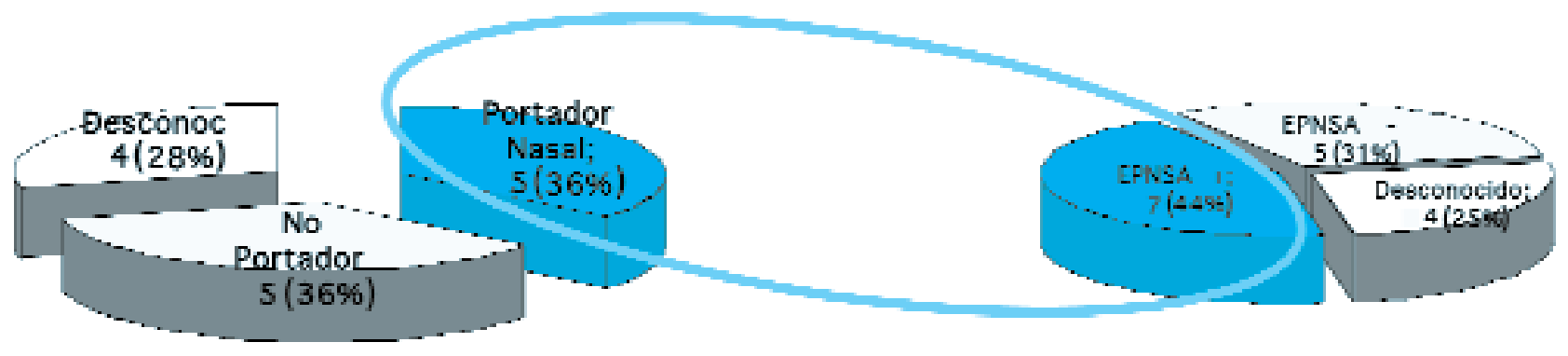

Figura 3. Relación entre portador nasal SA (EPNSA) e infecciones del acceso vascular.

- Evidenciamos una estrecha relación entre la condición de ser portador nasal del S. aureus y los casos de infección del acceso vascular.

- Puesto que el procedimiento de detección del Staphylococcus aureus es sencillo y de bajo coste, sería recomendable instaurar un protocolo de profilaxis de infecciones por este microorganismo a todos los pacientes de nueva incorporación en un programa de hemodiálisis.

\section{BIBLIOGRAFÍA}

- Boelaert JR, Van Landuyt HW, Godard CA, Daneels RF, Schurgers ML, Matthys EG, De Baere YA, Gheyle DW,
Gordts BZ, Herwaldt LA. Nasal mupirocin ointment decreases the incidente of Staphylococcus aureus bacteraemias in haemodialysis patients. Nephrol Dial Trasplant 1993; 8:235-239.

- Daurgidas JT, Todds SI. Manual de diálisis. Barcelona: Masson; 1996.

- Kessler M, Canaud B, Pedrini MT, Tattersall JE, ter Wee PM, Vanholder R, Wanner C. European Best Practice Guidelines for Haemodialysis (Part 1). Nephrol Dial Trasplant 2002; 17 (Suppl. 7).

- Llach F, Valderrábano F. Insuficiencia Renal Crónica. Diálisis y Trasplante Renal. 2 ed. Madrid: Ed. Norma; 1997. 